\title{
Editorial: Education with Heft
}

\section{Lisa Freinkel, Vice Provost for Undergraduate Studies, Associate Professor of English and Comparative Literature}

Some of my best friends are words.

I mean that quite, well, literally. I'm a language and literature person - having inhabited a world of signifying shapes and sounds with great delight since I first cozied up with the little bunny tucked in her little bed: "Goodnight moon, goodnight room...."

Of the many pages I have turned, and the many words I have loved, there's something about the word "heft" that has long struck me as resonant in an almost onomatopoeic way. Heft: a late derivative of "heave" signifying weight, heaviness, ponderousness. With its Germanic origins, its fricative "f" followed by the full dental stop of "t," the word itself sounds hefty, weighty, possessed of bulk. In this world of plastic and plywood, where so many of the objects that surround us are built for the moment, consumed in a heart beat, and consigned to a landfill: I am consistently drawn to those objects and practices that carry a bit of heft.... I am fan of that which thuds solidly onto the balance of our lives.

And so I remember with considerable joy and detail May 15, 1987: the completion of my undergraduate thesis in literature. In those hoary days, completing such a document required all manner of material support: spine clamp binders, typewriter ribbons, acid-free paper, six-inch rulers to measure off margins, and many caffeinated, perfectionist hours. And then it was done. I remember collapsing in the Quad on a beautiful Spring day, cradling the bound and finished document on my lap - feeling its weight and marveling at the perfect ink impression of each letter. This was a document with some heft. When I turned it in to my home department, I gave my advisor a fine cigar. A thesis is born! He held the thesis for a moment, then let it fall to the ground where, indeed, it thudded resoundingly. "Summa," he declared, laughing. (Too bad that grading doesn't indeed happen by the ounce!)

The experts in Higher Education studies will tell you that undergraduate research in its many forms is a "high impact practice": it offers a dramatic opportunity for student engagement and success. I couldn't agree more. Those of us involved in undergraduate research as students, advisors or mentors have seen at close range those amazing "aha" moments when something is uncovered on the very front lines, at the very cutting edge, of human culture and knowledge. Whether these contributions take place in a lab, in the archives, with a museum installation, in a dance studio, at a drafting table, at an easel, on the stage, or even in the streets: we all know that undergraduate innovation transforms undergraduate lives. 
But instead of high impact, I'd like to talk about the heft of these moments. In our pixilated and digitized lives, undergraduate research transforms us because there's something about discovery and innovation that feels substantial. Weighty. Real.

That sense of substance: of a lasting and authentic intervention in the age-old human work of meaning-making and comprehension.... Even here, in this digital journal hosted within the evanescent medium of the Internet, that sense of heft can be felt.

This is education with heft. Enjoy. 